\title{
INTRODUÇÃO \\ POTÊNCIA DAS DIFERENÇAS, DOS AFETOS E DAS MEMÓRIAS NOS DISCURSOS DE GÊNERO E SEXUALIDADES*
}

Viviane Melo de Mendonça

Kelen Christina Leite

Este é um livro de pesquisas, ensaios e memórias. É um livro que narra a constituição de um grupo de pesquisa. São lembranças, reflexões, estudos e resultados de pesquisas que pretendem provocar a discussão de gênero, diferenças e sexualidades. Então é assim que temos denominado este grupo de pesquisa: Núcleo de Estudos de Gênero, Diferenças e Sexualidades da Universidade Federal de São Carlos, campus Sorocaba (NEGDS-UFSCar).

O NEGDS-UFSCar é um grupo de pesquisa interdisciplinar do Departamento de Ciências Humanas e Educação da UFSCar, campus Sorocaba, que foi criado em 2014 com o objetivo de realizar estudos, pesquisas e divulgação de conhecimentos nas áreas de estudos feministas, de gênero e das sexualidades. A premissa principal do grupo é que os estudos de gênero, das diferenças e das sexualidades se constituem como uma prática acadêmica política, transformadora e necessariamente afetiva e interdisciplinar.

As discussões do grupo abordam os aspectos ontológicos e epistemológicos, éticos e estéticos dos estudos de gênero e das sexualidades, analisados juntamente com os demais marcadores sociais das diferenças, tais como classe, raça/etnia, sexualidade e idade. Muitos dos temas de pesquisa realizados na história do NEGDS-UFSCar relacionam-se com memória e representação, no sentido de identidades, fronteiras e pertencimento; participação política, educação, movimentos sociais e direitos humanos; trabalho e precariedade; e ainda mídias, tecnologias, ciência e cultura. Todos estes temas discutem as teorias de gênero e feministas contemporâneas criticamente. O NEGDS-UFSCar possui duas linhas de

*DOI - 10.29388/978-65-86678-12-3-f.11-16 
pesquisa: (a) Estudos feministas, Sexualidade e Política; (b) Memória, Gênero e Diversidade Sexual.

Os participantes do NEGDS-UFSCar, em sua maioria presentes neste livro, são diversos: docentes, estudantes de graduação e pós-graduação, militantes e profissionais de diversas áreas interessados na temática. Estas pesquisas também são produzidas no âmbito de duas pós-graduações da UFSCar, campus Sorocaba: Pós-graduação em Educação e Pósgraduação em Estudos da Condição Humana.

É das produções e inspirações das pesquisas do grupo que trazemos aqui os capítulos que tecem o livro. De um modo geral, tratamos neste livro sobre a potência das diferenças, dos afetos e das memórias nos discursos de gênero e sexualidades. Algumas outras inspirações marcam o trabalho do grupo: bell hooks, Judith Butler, Audre Lorde, Rosi Braidotti, Conceição Evaristo, Lélia Gonzales, Glória Anzaldúa, Michele Perrot, mas também Eclea Bosi, Karl Marx, Walter Benjamin, Michel Foucault, Gilles Deleuze e também, obviamente, Paulo Freire. É do diálogo, contradições e embates entre estes/as autores/as que a potência intelectual e acadêmica emerge nas pesquisas e ensaios aqui apresentados.

Temos a noção de afeto do filósofo Baruch Spinoza como guia, que inevitavelmente nos leva para a poesia, ou para um retorno à poesia e a arte em geral, e também a poesia como poiesis, no sentido etimológico da palavra, como constituinte do ser e das subjetividades. É no campo do sentido de uma escuta clínica deste social que nos pautamos. Quando tratamos de diferenças, afetos e memórias, a escuta sensível é um traço fundamental na formação do/a pesquisador/a. Quando neste campo o tema específico de gênero e sexualidades nos interpela, nos clama, esta escuta sensível é absolutamente central. E é com esta premissa que desenvolvemos as discussões das pesquisas.

Parte-se, aqui, desta citação do ensaio "A transformação do silêncio e linguagem e em ação" da poeta Audre Lorde:

E nos lugares em que as palavras das mulheres clamam para serem ouvidas, cada uma de nós devemos reconhecer a nossa responsabilidade de buscar essas palavras, de lê-las, de compartilhá-las e de 
analisar a pertinência delas na nossa vida. Que não nos escondamos por detrás das farsas de separações que nos foram impostas e que frequentemente aceitamos como se fossem invenção nossa. Por exemplo: "Provavelmente eu não posso ensinar literatura feita por mulheres negras - a experiência delas é diferente demais da minha". E, no entanto, quantos anos vocês passaram ensinando Platão, Shakespeare e Proust? Outra: "Ela é uma mulher branca, o que teria para me dizer" Ou: "Ela é lésbica, o que meu marido, ou meu chefe, diria?" Ou ainda: "Essa mulher escreve sobre filhos e eu não tenho filhos". E todas as outras incontáveis maneiras de nos privarmos de nós mesmas e umas das outras.

Podemos aprender a agir e a falar quando temos medo da mesma maneira que aprendemos a agir e a falar quando estamos cansadas. Fomos socializadas a respeitar mais o medo do que nossa necessidade de linguagem e significação, e enquanto esperarmos em silêncio pelo luxo supremo do destemor, o peso deste silêncio nos sufocará.

O fato de estarmos aqui e de eu falar essas palavras é uma tentativa de quebrar o silêncio e de atenuar algumas das diferenças entre nós, pois não são elas que nos imobilizam, mas sim o silêncio. E há muitos silêncios a serem quebrados. (LORDE, 2019, p.55)

O que Audre Lorde vem nos dizer em momentos de adoecimento psíquico e físico, de violência e medo da morte de pessoas consideradas abjetas, para quem é negado o direito à respiração, à vida e ao luto?

Parece que Lorde (2019) está nos dizendo (ou o que escutamos ela nos dizendo) que o silêncio, o silenciamento provocado pelo medo/ violência/opressão, não pode mais continuar. Assim, ela diz para as mulheres e grupos subalternizados, com precisão, que o silêncio não as/os protege. O medo do desprezo, o medo da censura, o medo do sufocamento, o medo da aniquilação, que as/os têm deixado em silêncio, não as/os protegem, apenas as/os jogam no campo da invisibilidade, como corpos abjetos, que não têm o direito à respiração. 'I can't breath”, dizem os sufocados pelo Estado e pela sociedade e polícia racista, mas também lesbohomobitransfóbica. 
Onde podemos escutar nestas palavras o desejo de resistência? Aquele desejo que se espraia, que entra nas brechas do cotidiano, que, para usar as palavras de Birman (2017, p.235), se afirma estridentemente diante da perplexidade, do conservadorismo e da violência de nossos tempos. Como ouvir os corpos que não podem dizer seu nome e os amores que não podem dizer seu nome? Como transformar a resistência em desejo, em desejo que nos move para a efetivação da mudança pessoal e coletiva? Como dito por Audre Lorde (2019), como transformar o silêncio em linguagem e ação? Eis uma tarefa que temos parte no campo acadêmico-científico e quando pensamos socialmente e politicamente em uma sociedade igualitária.

As pesquisas aqui apresentadas partem do reconhecimento da condição de positividade epistemológica que a afetividade ocupa na existência humana, considerando-a como constitutiva do sujeito e das subjetividades, do pensamento e da ação, no âmbito individual e coletivo. A afetividade na condição humana é aqui considerada um fenômeno ético, estético e político, pertencente à ordem do encontro, e construída nas relações sociais, mediante o modo como o sujeito afeta e é afetado pelos outros. Os sujeitos são afetos, desejos, sentimentos e paixões, situados em sua condição material de existência. Daí a influência da filosofia dos afetos desenvolvida por Spinoza. O afeto é entendido como as afecções do corpo pelas quais a potência de agir desse corpo é aumentada ou diminuída, favorecida ou reduzida (SPINOZA, 2010).

$\mathrm{Na}$ constituição do sujeito, a dialética exclusão/inclusão social tende a provocar o sofrimento e a dor psíquica que são originados da situação social de ser tratado como inferior ou como subalterno. E este é o sofrimento, em grande parte, presente nos relatos de pessoas LGBTQI+ e de mulheres. Com base nas argumentações de Sawaia (2001), inspirada em Spinoza, este é um "sofrimento ético-político", visto que é constituído nas relações sociais e de poder, ou seja, na vivência cotidiana da desigualdade social e da exclusão da maioria destas pessoas dos meios de produção material, cultural e social, e produz um tipo de sofrimento resultante da "consciência do sentimento de desvalor, da deslegitimidade social e do desejo de 'ser gente”" (SAWAIA, 2001, p. 114). 
Portanto, a superação do sofrimento ético-político tem em sua agenda a emancipação dos sujeitos, que o potencializa para a ação política e transformadora de si e da sociedade. Potencializar para ação pressupõe o desenvolvimento de valores éticos e estéticos de sentimentos, desejos e necessidades. Esta talvez seja a proposta quando falamos do papel político-acadêmco na produção de conhecimentos que articula gênero, sexualidade, classe e raça

Isto é o que chamamos de afetivizar a escuta, torná-la clínica e sensível. É dar condições para o encontro que produz a palavra própria, tal como colocado por Paulo Freire no campo da educação popular; e, deste modo, potencializar para a ação que provoca a mobilização dos significados, sentimentos e emoção, coletivas e individuais, frente à dialética exclusão-inclusão social geradora de sofrimento ético-político nos termos de Sawaia (2001). É transformar o silêncio em linguagem e ação, como diria Audre Lorde.

E o que a memória tem a ver com isso? É porque são com narrativas de memórias que trabalhamos, sejam de perto ou de longe. Quando escutamos as memórias mobilizamos afetos, uma escrita de si, novas subjetividades e novos modos de existência. Ouvir as memórias de mulheres e pessoas LGBTQIA+ não é uma atitude passiva, mas é de criação de efetivos espaços para que estas pessoas possam falar e possam ser ouvidas, porque ao falarem e ao serem ouvidas age-se contra a "subalternização" destes corpos (SPIVAK, 2010) e, assim, cria-se um lugar fundamental onde elas possam se articular e produzir uma vida politico-afetivamente potente de ação e linguagem e, por conseguinte, de superação da tradição do silenciamento e do sofrimento psíquico que paralisa a existência, que as calam e que as fazem perder o fôlego de vida.

Para encerrar, estamos aqui em momento de virada afetiva, inspirada também no monismo spinozano, segundo a filósofa feminista Rosi Braidotti (2019). São signos, palavras e narração produzidos como artesanatos na intensidade da experiência. Assim, ter voz é respirar, é narrar suas experiências, é encontrar e se apropriar de suas memórias, é engendrar Utopia e produzir um mundo respirável. Conforme Walter Benjamim (2012), é resgatar dos escombros a experiência, a arte de contá-las e, por outro lado, a arte da escuta. Os capítulos apresentados neste livro pa- 
recem ser, diante de um mundo racista, misógino e lesbohomobitransfóbico, um trabalho artesanal de criação de espaços de escutas sensíveis e críticas, de novas subjetividades, novas existências e de nossas utopias do presente, um mundo ética e politicamente viável. Porque não, não são as nossas diferenças que nos separam, mas os nossos silêncios, e foi isso o que disse e nos ensinou Audre Lorde (2019).

Boa leitura.

\section{Referências}

BENJAMIN, Walter. O narrador. In: BENJAMIN, Walter. Magia e Técnica, arte e política: ensaios sobre literatura e história da cultura. São Paulo: Brasiliense, 2012.

BRAIDOT'TI, Rosi. A Theoretical Framework for the Critical Posthumanities. Theory, Culture \& Society, v. 6, n. 36, p. 31-61, 2018. BIRMAN, Joel. Arquivos do mal-estar e da resistência. Rio de Janeiro: Civilização Brasileira, 2017.

LORDE, Audre. A transformação do silêncio e linguagem e em ação. In: LORDE, Audre. Irmã outsider. Belo Horizonte: Ed. Autêntica, 2019. p. 51-66.

SAWAIA, Bader B. O sofrimento ético-político como categoria de análise da dialética exclusão/inclusão. In: SAWAIA, Bader B (Ed.). As artimanhas da exclusão: análise psicossocial e ética da desigualdade social. Petrópolis, RJ: Vozes, 2001. p. 97-118

SPINOZA, Baruch. Ética. Belo Horizonte: Autêntica Editora, 2010.

SPIVAK, Gayatri C. Pode o subalterno falar? . Belo Horizonte: UFMG, 2010. 